\title{
Measurement and Analysis of Vibration of Operator in Universal 650, Massey Ferguson 285 \& MF 299 Tractors
}

\author{
Mohsen Fereydooni ${ }^{1}$, Ali Nejat Lorestani ${ }^{2, *}$, Hekmat Rabbani' ${ }^{2}$, Payam Javadikia $^{2}$ \\ ${ }^{1}$ Agricultural Faculty, Razi University, Kermanshah, 6741744475, Iran \\ ${ }^{2}$ Mechanical Engineering of agricultural machinery Department, Agricultural Faculty of Razi University, Kermanshah, Postal code: \\ 6715685438, Iran
}

\begin{abstract}
Since healthy human is basis of permanent development in any society, and safety \& health subject have special importance, then examination and investigation is necessary about of risks working for the purpose of recognition danger and guiding to eliminate them. In this study, object is to compare effect of change engine rotation and ground type on operator of tractors and implements that utilized. In other words, the goal is to measurement and analysis of transmitted vibration on different parts of human body. In this investigation universal tractor and ferguson285 \&299 tractors with moldboard plough and disk are used. Hand-Arm vibration's operator in 1300, 1500 and $1700 \mathrm{rpm}$ and in ploughing field and unploughing field with hand-arm vibration meter are measured. After statistical analysis, appeared that effective vibration difference on hand and arm's operator in examined tractors is significant and engine rotation is significant too.
\end{abstract}

Keywords Agriculture, Hand \&Arm, Safety, Tractor, Vibration.

\section{Introduction}

Types of mechanical equipments that produce a lot of vibration force can cause hand-arm vibration in the tractor operator, and increasing use of such equipments can cause discomforts such as soft tissue damage, calcium loss in the hand and arm joints and the vascular damage that white finger disease is the most common complication of this type of vibration.

Whilst exposure to vibration is traditionally regarded as perilous, recent research has focused on potential benefits. Literature suggests that vibration is beneficial to reduce chronic lower back pain and other type of pain,[12]. As the complexity of a tractor and its operation environment, the design of a tractor using the traditional method is a long period and high cost process. With the development of the theory of vehicle and terrain systems and multi-body dynamics, it is feasible for us to design a tractor or analyze its performance using the techniques of modeling and simulation. The vibration of wheeled tractors traveled on the rough ground was studied while the mechanics mode and equation of vibration was set up,[15]. Conduits are important elements of the fuel systems of cars, tractors, ships, planes, etc. Their vibrations often cause drumming, leading to discomfort for crew members and passengers. This is due to the fact that the frequency spectra of conduit

* Corresponding author:

ali.lorestani@gmail.com (Ali Nejat Lorestani)

Published online at http://journal.sapub.org/mechanics

Copyright (C) 2012 Scientific \& Academic Publishing. All Rights Reserved vibrations are sometimes in a range hazardous to human health,[1].

Shock-type vibrations are frequently experienced in vehicles excited by impulsive input, such as bumps in the road, and cause discomfort. Current national and international standard weightings were primarily developed for assessing exposure to sinusoidal or random vibrations and not impulsive excitations or shocks,[13]. An inseparable part of the development of the current automotive industry is the application of new components of vibration isolation, [8].

A sensorimotor treatment based on a set of customized voluntary movements is tested to counter and prevent potential post-work accidents due to prolonged exposure to whole body vibration,[9]. Exposure to whole body vibrations predicts subsequent disability pension retirement continue reduction of whole-body-vibrations may reduce the number of new cases of disability pension,[2]. A new tyre model for use in off-road vehicle ride vibration studies is proposed. It was incorporated in a three dimensional tractor model and then tested by comparing predicted vibration results with measured for ten tractors over a range of speeds on a known surface,[3]. A dynamic three-dimensional model was constructed for a half-track tractor that considers its bounce, pitch and roll motion in order to clarify the tractor's vibration characteristics,[6]. The cushioning material in a tractor seat plays a dominant role in supporting operator posture, isolating vibration and improving ride quality. Vibration attenuation in a tractor seat is achieved by selecting proper suspension and damping mechanism,[14]. Suspended cabin tractor 
semi-trailer drivers are exposed to whole body vibration during their work. The practical significance of applying suspended cabin type of tractor semi-trailer was tested conditions, different speeds. Gentic algorithm is used to optimize the whole body vibration of suspended cabin tractor semi-trailer drivers,[10]. Tuning algorithms of both the rolling profile and the feedback controllers gains such that the mechanical vibration in the legged vehicle during locomotion is attenuated. As a result, stable and smooth locomotion is obtained. The effectiveness of the proposed method is demonstrated by experimental results,[11]. To minimize the noise carried to oprators, the use of tractors with original cabins should be increased. While choosing places for forest depots, steeply sloped areas should be avoided, and the roughness of the ground should be reduced by covering the ground of existing depots with stabilized material,[7].

In this study, Universal 650, Massey Ferguson 285, 299 tractors with moaldboard plough and disk were used. Then Hand and arm vibration affecting the operator was measured with an oscillator in 1300, 1500 and 1700rpm on ploughing and unploughing field.

\section{Materials and Methods}

\subsection{Vibration Meter Entroducing}

Oscillator $^{1}$ was used for measuring hand-arm vibration of operator. In this device, using the main parameters of vibration such as acceleration, velocity and displacement that are named according to the figure 1 , vibration levels in three directions as longitudinal, transverse and lateral were measured.

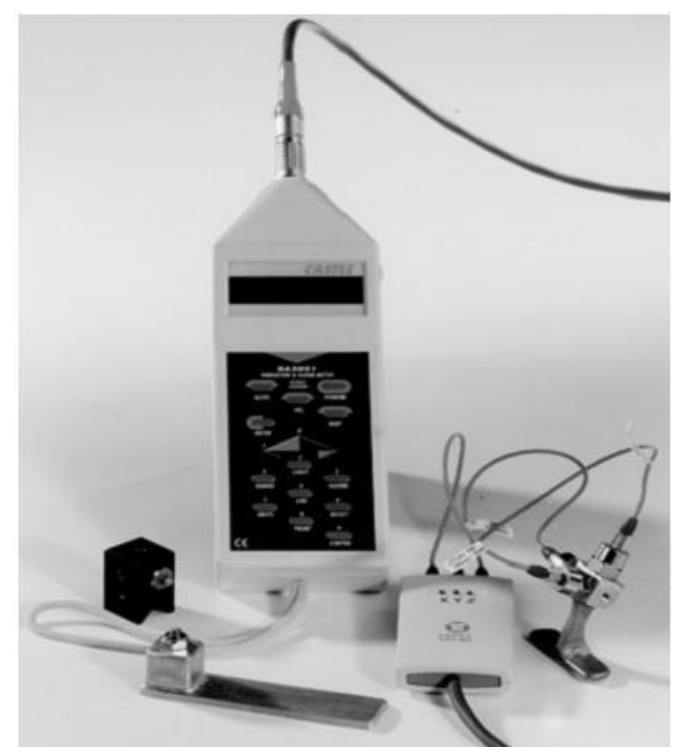

Figure 1. Vibration meter that used

Exprimental design used is type of factorial that based on randomized complete block, where the three factors are used that each with two levels. Three types of tractors with three engine rotation in the two types of ground binding two types of agricultural equipment (moaldboard plough and disk) are examined.

With the amount of longitudinal vibration, the vibration of transverse and lateral vibration, and using formula 1 the weighted vibration can be calculated,[5].

$$
\mathrm{V}=\left[\mathrm{k}_{\mathrm{x}}{ }^{2} \mathrm{a}_{\mathrm{wx}}^{2}+\mathrm{k}_{\mathrm{y}}{ }^{2} \mathrm{a}^{2}{ }_{\mathrm{wy}}+\mathrm{k}_{\mathrm{z}}{ }^{2} \mathrm{a}^{2}{ }_{\mathrm{wz}}\right]^{1 / 2}
$$

Where

$\mathrm{V}$ is the resultant vibration weighted.

$a_{w x} \cdot a_{w y}, a_{w z}$ : the weighted vibration levels in three direction.

The values in formula 1 are (Iso 2631-1, 1997),[4]: $\mathrm{K}_{\mathrm{x}}=1.4, \mathrm{k}_{\mathrm{y}}=1.4, \mathrm{k}_{\mathrm{z}}=1.0$

In order to perform statistical analysis plan, Excel and SPSS 19 software was used.

\subsection{Entrance Direction of Vibration}

Human reaction is different to entrance direction of vibration from the point of view of mechanical, mental and physiological cases. Therfore, human endurance is different. Entrance direction of vibration to human body in three direction is $\mathrm{x}, \mathrm{y}$ and $\mathrm{z}$. $\mathrm{X}$ direction is from behind of head to front of heart. $\mathrm{Y}$ direction is from right shoulder to left shoulder. $\mathrm{Z}$ direction is from legs to head. Vibration measuring should be on base of methods and measuring instrument that suggest by ISO 5349 and ANSI S3. 34 in 1986. That briefly is acceleration of handlebar of a tool or vibrating part shoud be in three direction that are perpendicular to themselves and vibration shoud be measure in near to entrance place. Preferencely the above-mentioned axis shoud to coincide on Biodynamic system axis. Thus it is possible are placed to near the Basicentric system (according to Fig. No. 2).

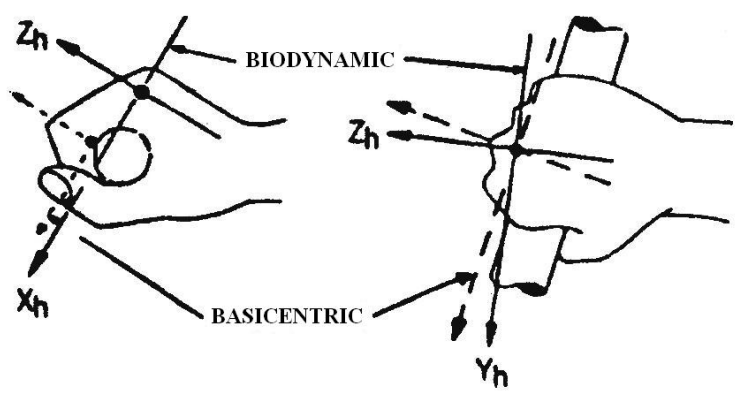

Figure 2. Presentation of Biodynamic system axis and Basicentric system

\subsection{Hand-Arm Vibration}

Hand-transmitted or hand-arm vibration occurs whenever an individual holds a vibrating tool. Most of the literature relating to the perception of hand-transmitted vibration has been based on psychophysical experiments in which subjects are exposed to vibrations with an extended hand resting lightly on a vibrating prob.

\subsection{Whole-body Vibration}

Whole-body vibration occurs when a human is supported by a surface that is shaking and the vibration affects body 
parts remote from the site of exposure. For example, when a forklift truck drives over a bumpy surface, vibration is transmitted through the vehicle to the seat and footrest, which are the surfaces that support the driver. The vibration is then transmitted through the body of the driver to the head, which will move. This transmission path includes the seat, the surface of the driver in contact with the vehicle including the driver's nervous system, the skeleton including the spine where an injury might occur, and ultimately the skull which might have its own dynamic responses to the transmitted vibration. Two technically identical standards, Iso 6897 (1984) and BS 6611 (1985) provide guidance for assessing the motion of tall buildings or fixed offshore structure to low-frequency motion $(0.063$ to $1 \mathrm{HZ}$ ). The standards provide a "satisfactory" magnitude of motion for the peak $10 \mathrm{~min}$ of the worst windstorm with a return period of 5 years. For building motion, satisfactory magnitudes are belpw $0.067 \mathrm{~m} / \mathrm{s}^{2}$ r.m.s. at $0.1 \mathrm{~Hz}$ falling to $0.026 \mathrm{~m} / \mathrm{s}^{2}$ r.m.s. at $1 \mathrm{~Hz}$. These values do not consider other cues to the motion such as visual or auditory.

\section{Results and Discussion}

\subsection{Tractor Analysis}

The results of variance analysis of tractor and engine rotation treatments that are tested respectively are shown in tables 1 .

Table 1. ANOVA of main factors and their interaction effects on vibration area in tractors that examined

\begin{tabular}{ccccc}
\hline Source of variation & df & $\begin{array}{c}\text { Sum of } \\
\text { squares }\end{array}$ & $\begin{array}{c}\text { Mean } \\
\text { squares }\end{array}$ & F-value \\
\hline Tractor type (A) & 2 & 4.552 & 2.276 & $521.248^{* *}$ \\
Engine rotation (B) & 2 & 1.088 & 0.544 & $124.559^{* *}$ \\
Ground type (C) & 1 & 0.853 & 0.853 & $195.420^{* *}$ \\
Implement type (D) & 1 & 4.754 & 4.754 & $1088.795^{* *}$ \\
$\mathrm{~A} \times \mathrm{B}$ & 4 & 0.054 & 0.013 & 3.073 \\
$\mathrm{~A} \times \mathrm{C}$ & 2 & 0.739 & 0.369 & $84.590^{* *}$ \\
$\mathrm{~A} \times \mathrm{D}$ & 2 & 1.220 & 0.610 & $139.746^{* *}$ \\
$\mathrm{~B} \times \mathrm{C}$ & 2 & 0.062 & 0.031 & $7.085^{* *}$ \\
$\mathrm{~B} \times \mathrm{D}$ & 2 & 0.157 & 0.079 & $18.032^{* *}$ \\
$\mathrm{C} \times \mathrm{D}$ & 1 & 0.231 & 0.231 & $53.011^{* *}$ \\
$\mathrm{~A} \times \mathrm{B} \times \mathrm{C}$ & 4 & 0.027 & 0.007 & 1.542 \\
$\mathrm{~A} \times \mathrm{B} \times \mathrm{D}$ & 4 & 0.113 & 0.028 & $6.483^{* *}$ \\
$\mathrm{~A} \times \mathrm{C} \times \mathrm{D}$ & 2 & 0.376 & 0.188 & $43.047^{* *}$ \\
$\mathrm{~B} \times \mathrm{C} \times \mathrm{D}$ & 2 & 0.004 & 0.002 & 0.465 \\
$\mathrm{~A} \times \mathrm{B} \times \mathrm{C} \times \mathrm{D}$ & 4 & 0.032 & 0.008 & 1.856 \\
$\mathrm{E} r \mathrm{Nor}$ & 72 & 0.314 & 0.004 & \\
$\mathrm{~T} \times t a 1$ & 108 & 30.556 & & \\
\hline & & & & \\
\hline & & &
\end{tabular}

**The mean difference is significant at the .01 level

Since according to table 1, the mean difference between tractor treatments have a significant difference with $1 \%$ level. So we can say that the tractor operator in Massey Ferguson 285 will be less affected by vibration than Massey Ferguson 299, and tractor operator in Massey Ferguson 299 will be less affected by vibration than Universal 650 too (according to Fig. No. 3).

\subsection{Engine Rotation Analysis}

On the other hand, according to table 1 the mean difference between engine rotation treatments has a significant difference with the $1 \%$ level. So we can say that the tractor operator while working at lower engine rotation is less affected by vibration. As the interaction of implements is shown in figure 4 .

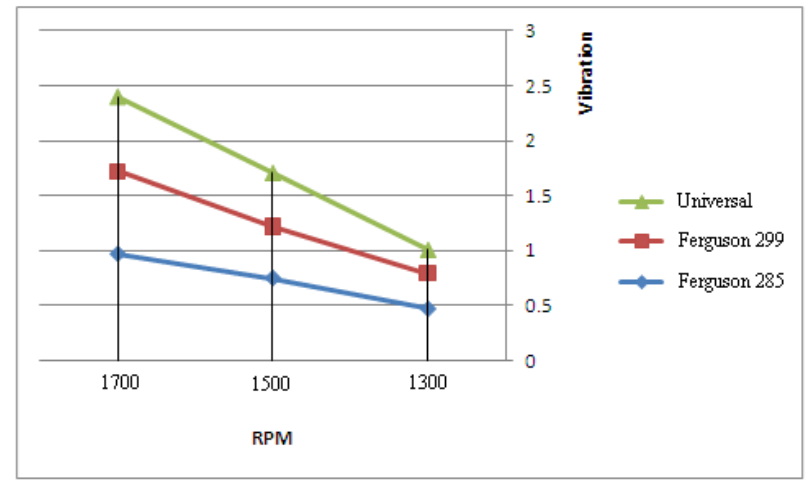

Figure 3. display interaction of engine's rotations that examined

Table 2. ANOVA of Engine Rotation

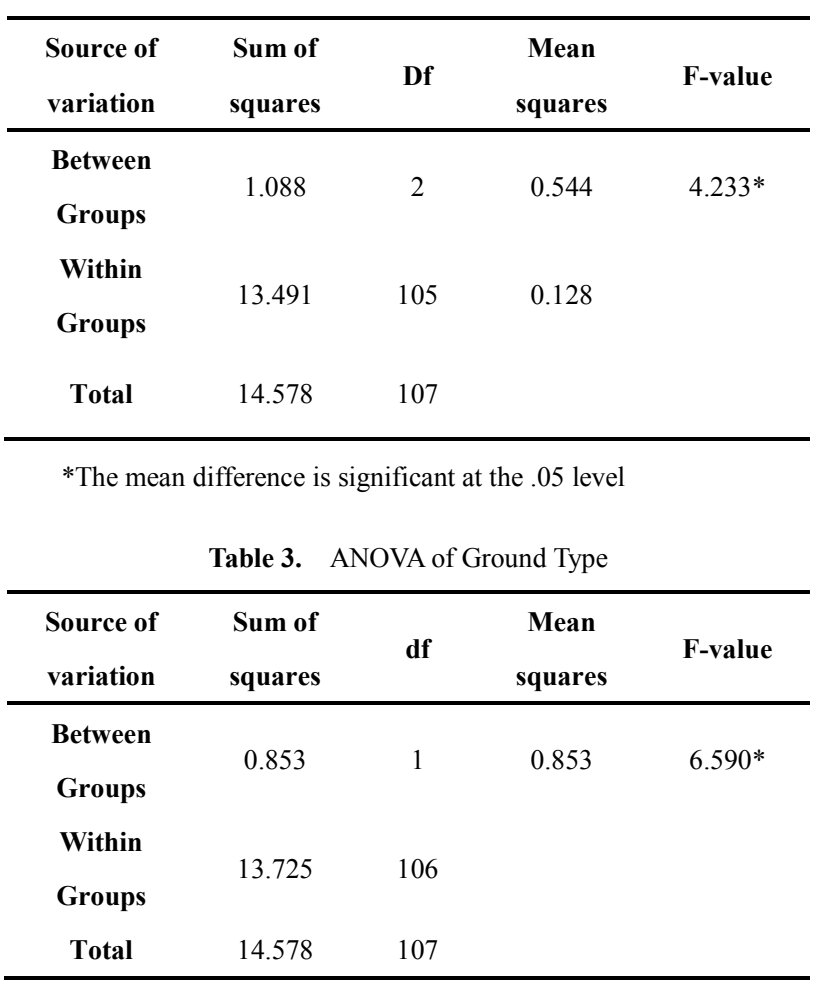

*The mean difference is significant at the .01 level

\subsection{Implement Analysis}

As the interaction of implements is shown in figure 5, then it can be concluded that disking operator exposure to 
less vibration than he worked with moldboard plough while working on the same terms.

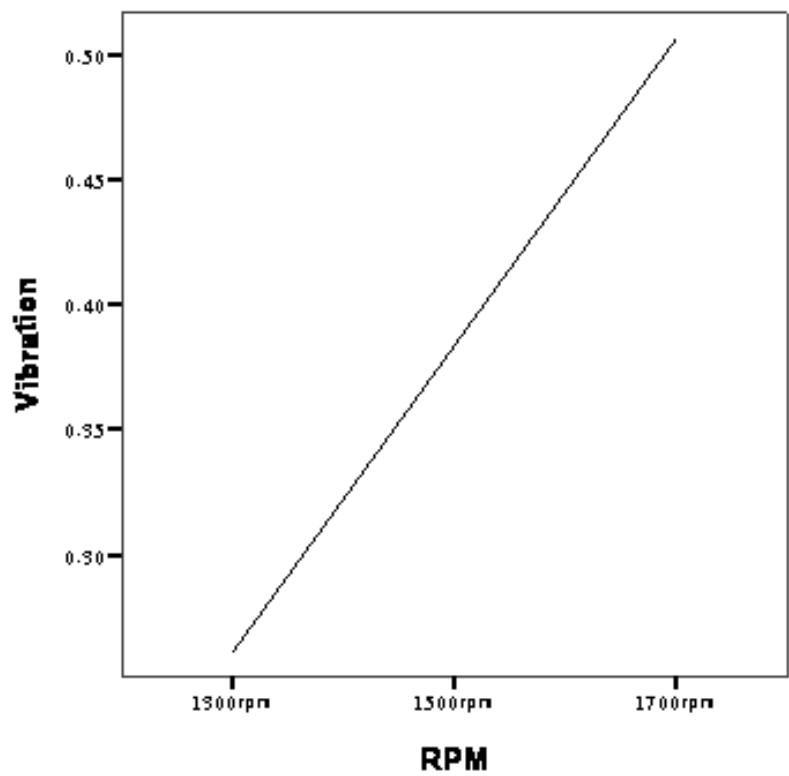

Figure 4. display interaction of engine's rotations that examined with all the three tractors

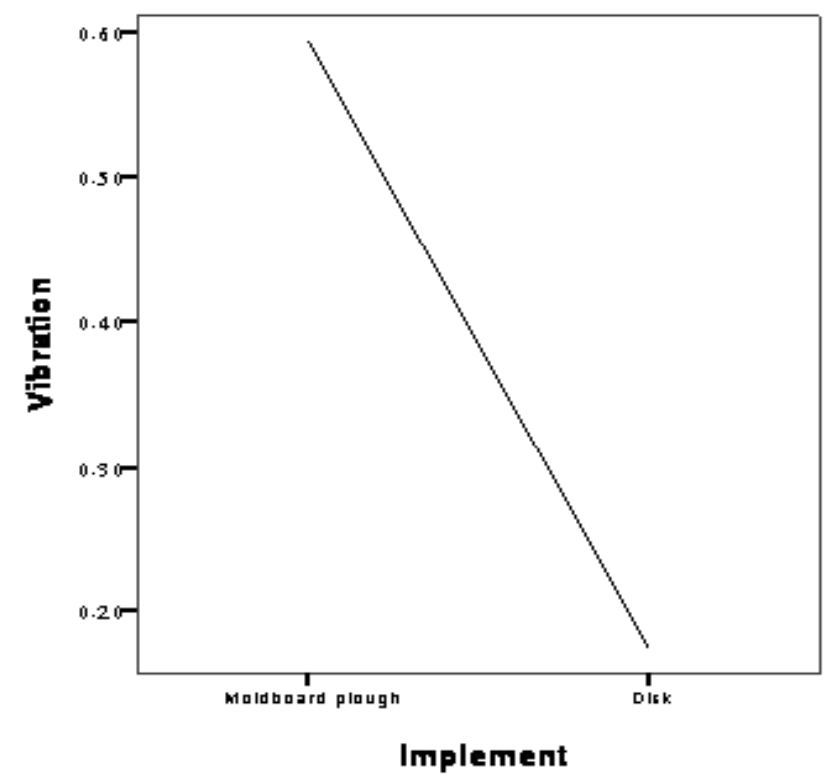

Figure 5. display interaction of implements that examined with all the three tractors

Table 4. ANOVA of Implement Type

\begin{tabular}{ccccc}
\hline $\begin{array}{c}\text { Source of } \\
\text { variation }\end{array}$ & $\begin{array}{c}\text { Sum of } \\
\text { squares }\end{array}$ & df & $\begin{array}{c}\text { Mean } \\
\text { squares }\end{array}$ & F-value \\
\hline Between & 4.754 & 1 & 4.754 & $51.299^{* *}$ \\
Groups & & & & \\
Within & 9.824 & 106 & 0.093 & \\
Groups & 14.578 & 107 & \\
Total & 107 & \\
\hline
\end{tabular}

**The mean difference is significant at the .01 level

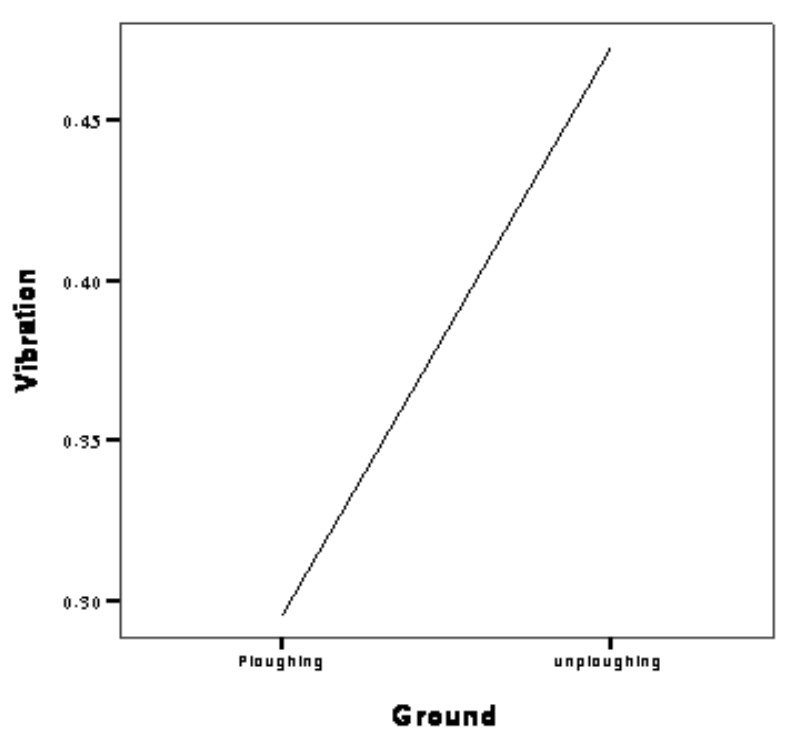

Figure 6. display interaction of type of ground that examined with all the three tractors

\subsection{Ground Analysis}

As the interaction of kind of testing ground are shown in figure 6 , then it can be concluded that operator exposure to less vibration on plough ground than he worked on unplough ground while working on the same terms.

\section{Conclusions}

Based on the results of statistical analysis, we can conclude that at the same terms the lowest vibration occurs respectively working with Massey Ferguson 285, 299 and Universal 650 tractors. Disking operator exposure to less vibration than he worked with moldboard plough and operator exposure to less vibration on plough ground than he worked on unplough ground. However increasing the engine rotation will increase vibrations on operator.

\section{Note}

\section{GA2001 HARM Vibration meter}

\section{REFERENCES}

[1] A.M. Akhtyamov, G. F. Safina, "Vibration-Proof conduit fastening", in Proceedings of Fizika, Institute of Mechanics, vol.49, no.1, pp. 139-147, 2008.

[2] Finn Tuchsen, Helene Feveile, Karl B Christensen and Niklas Krause. "The impact of self-reported exposure to whole-body-vibrations on the risk of disability pension among men: a 15 year prospective study", in Proceedings of BMC. Public Health, vol.10, no. 305, pp., 2010.

[3] G. Molari, L.Bellentani, A. Guamieri, M. Walker, E. Sedoni, "Performance of an agricultural tractor fitted with rubber tracks", in Proceedings of Biosystem Engineering. vol.111, 
no.1, pp. 57-63, 2012.

[4] K. N. Dewangan, V. K. Tewan,. "Characteristics of hand-transmitted vibration of a hand tractor used in three operational modes", in Proceedings of Int. J. Industrial Ergonomics, vol. 39, no.1, pp. 239-245, 2009.

[5] Maleki, A., Mohtasebi, S., Akram, A. and Esfehanian, V. "Analysis, simulation and evaluation of human vibration and tractor", Thesis, Univ. of Tehran, Iran. 2008.

[6] M.A. Rabbani, T. Tsnjimoto, M. Mitsuoka, E. Inoue, T. Okayasn, "Prediction of the vibration characteristics of half-track tractor considering a three-dimensional dynamic model", in Proceedings of Biosystem Engineering, 2011.

[7] Melemez, K. and Tunay, M. "An Ergonomic Evaluation on Whole-Body Vibration of Loading Tractors in Turkish forestry.ui Meeting the Needs of the Society and the Environment", Dissertation, Univ. of Forestry Faculty, Turkey, 2010.

[8] N. A. Dokukova, P. N. Konon, E. N. Kaftaikina. "Nonnatural vibrations of hydraulic shock-absorbers", in Proceedings of Int. J. of Engineering Physics and Thermophysics, vol.81, no.6, 2008.

[9] Olivier Oullier, Anne Kavounoudias, Cyril Duclos, Fredric Albert, Jean-Pierre Roll, Regine Roll. "Countering postural posteffects following prolonged exposure to whole-body vibration: a sensorimotor treatment" , in Proceedings of Eur. J. Appl Physiol, vol.105, no.10, pp. 235-245, 2009.
[10] P. Velmurugan, L. A. Kumaraswamidhas, K. Sankaranarayanasamy, "Optimisation of whole body vibration analysis for suspended cabin tractor semitrailer" , in Proceedings of Int. J. of Vehicle Noise and Vibration, vol.8, no.2, pp. 152-165, 2012.

[11] Riadh Zaier, Jamil Abdo. "Legged vehicle control and vibration reduction", in Proceedings of Int. J. of Vehicle Noise and Vibration 2012, Vol 8. no.1, pp. 74-94, 2012.

[12] Rittweger, J., "Vibration as an exercise modality: how it may work, and what its potential might be". Eur J Appl Physiol. vol.108, no.10, pp. 877-904, 2009.

[13] S.J.Ahn., "Discomfort of vertical whole-body shock-type vibration in the frequency range of 0.5 to $16 \mathrm{~Hz}^{\prime}$, in Proceedings of International Journal of Automotive technology, vol.11, 2010.

[14] V. k. Tewari, K. N. Dewangan, "Effect of vibration isolators in reduction of work stress during field opration of hand tractor", in Proceedings of Biosystem Engineering, 2009.

[15] Wenqian Huang, Feijun Xu, Jishuai Ge and Chi Zhang, "Simulated Analysis of a Wheeled Tractor on soft soil based on Recur Dyn", in Proceedings of IFIP AICT 370 International Federation for Information Processing, pp. 332-342, 2012. 